\title{
Effect of gestational Mediterranean diet intervention on newborn fat mass and cord blood leptin level
}

\author{
Rania Mohamed Abdou', Gehan Sayed El Hawary ${ }^{1}$ and Azza A. Saab ${ }^{3^{*}}$ (D)
}

\begin{abstract}
Background: Maternal nutritional status is an important determinant of intrauterine growth and neonatal size. No published surveys exist on maternal Mediterranean diet intakes and newborn adiposity. The aim of the study was to evaluate the impact of the individual maternal Mediterranean diet on the in-utero body fat formation and cord leptin level in newborns. Pregnant women with a pre-pregnancy body mass index (BMI) between 30 and $35 \mathrm{~kg} / \mathrm{m}^{2}$ $(n=118)$ were assisted for individual dietary counseling based on the Mediterranean diet healthy eating. According to diet adherence, participants (paired mother and newborn) were divided into an intervention group $(n=57)$ and a control group $(n=61)$. We examined the association between diet modification and gestational weight gain, maternal, and cord leptin level together with newborn anthropometry (weight and fat mass \%).

Results: Gestational weight gain, newborn birth weight, fat mass \%, and cord leptin level lower in the intervention $(12.22 \pm 1.8 \mathrm{~kg}, 3.57 \pm 0.35 \mathrm{~kg}, 9.27 \pm 2.16 \%, 11.78 \pm 3.63 \mathrm{ng} / \mathrm{ml}, p=000$, respectively) than in control group (18.03 $\pm 3.25 \mathrm{~kg}, 4.02 \pm 0.32 \mathrm{~kg}, 11.85 \pm 2.30 \%, 35.37 \pm 11.14 \mathrm{ng} / \mathrm{ml}$, respectively. Umbilical cord leptin levels strongly correlated with neonatal fat mass percent in both groups. However, maternal serum leptin did not correlate with the newborn parameters in the intervention group.
\end{abstract}

Conclusion: Maternal energy intake from healthy fat and diet intervention is probably associated with decreased fat mass and leptin levels in neonates.

Keywords: Fat Mass, Gestational weight gain, Mediterranean diet

\section{Background}

Maternal nutritional and metabolic conditions determine the environment in which the fetus develops. The intrauterine environment can permanently change and mark the baby's physiology and metabolism. This process is also known as fetal programming or fetal origin hypothesis [1]. Fetal metabolic programming was initially studied in the context of maternal undernutrition and/or reduced intrauterine growth. There is an emerging need to evaluate the effect of maternal adiposity on offspring. Adverse maternal environments during the pregnancy,

\footnotetext{
* Correspondence: azzasaab@yahoo.com

${ }^{3}$ Department of Clinical Pathology, Faculty of Medicine, Ain Shams University, Cairo, Egypt

Full list of author information is available at the end of the article
}

such as those seen with greater maternal body mass index (BMI) at the start of pregnancy and greater gestational weight gain (GWG) have been found to be associated with increased lifelong risks of offspring obesity and metabolic and cardiovascular dysfunction in adulthood [2]. However, little is known about metabolic adaptations in the offspring that occur independently of postnatal growth and nutrition. These metabolic diseases and conditions are now being diagnosed in children and adolescents at alarming rates, mirroring the rising rates of juvenile obesity [3].

The Mediterranean-style diet has been associated with reduced risk of cardiovascular disease, cancer, obesity, and metabolic syndrome $[4,5]$. Taking this a step further, research is now pointing to the benefits that 
adherence to a Mediterranean diet could have while pregnant [6].

Virtually, any nutritional or other factors on the maternal side must pass through the syncytioendothelial membrane to reach the fetal blood. In addition to mediating the transport of nutritional and metabolic compounds, the syncytio-trophoblast works as an endocrine organ that releases several hormones and growth factors to the maternal circulation. These factors effectuate profound metabolic and vascular alterations in the maternal body securing adequate conditions for fetal development [7].

Leptin is a polypeptide hormone that aids in the regulation of body weight and energy homeostasis and is linked to a variety of reproductive processes in both animals and humans. Fat mass is the major determinant of circulating leptin levels in children and adults, and cord blood leptin has been found to reflect neonatal fetal mass [8]. In the present study, we hypothesized that gestational adiposity may affect circulating levels of leptin and affect the fetal growth and body composition. Therefore, our aim was to evaluate the impact of individual maternal dietary counseling on the in-utero body fat formation and cord leptin level in newborns.

\section{Methods}

This was a cross-sectional study conducted at the antenatal clinic as a part of the gestational nutritional counseling program and neonatal intensive care unit of Ain Shams University Hospital for one and a half years starting June 2016. An informed consent was obtained from pregnant women to be enrolled in the study.

Eligibility included obese women with singleton uncomplicated pregnancies and BMI between 30 and $35 \mathrm{~kg} / \mathrm{m}^{2}$, attending the obstetric clinic of Ain Shams University Hospital, who continued the interventional nutritional counseling and gave birth at the hospital.

Exclusion criteria: multiple pregnancies, known women with pre-gestational or gestational diabetes and with severe chronic diseases (pulmonary, cardiac, or renal), and any discovered fetal malformation during routine follow-up or emerging diseases that could affect fetal growth and liver functions.

Eligible pregnant women were assisted to a preliminary nutritional education session and lifestyle changes. The interventional diet modification was based on the Mediterranean diet. The scheduled individualized session for nutritional counseling was performed every 4 weeks focusing on the nutritional requirements during pregnancy and the healthy balanced diet modification. A printed handout was given to each participant of the diet regimen required. Each pregnant woman had at least 3 recorded nutritional assessment visits throughout the pregnancy period.
The traditional Mediterranean diet is characterized by a high intake of olive oil, fruits, vegetables, legumes, nuts, and whole-grain products; a moderate intake of fish; and only small amounts of red and processed meat. This dietary pattern is low in saturated fat intake and high in monounsaturated fat intake from olive oil. Total fat in a diet roughly provides 25 to $35 \%$ of calories, with saturated fat providing $8 \%$ or less of calories). It is rich in fiber and glutathione, provides a balanced ratio of $n$ 6/n-3 essential fatty acids, and high amounts of antioxidants (especially polyphenols from olive oil, vitamins E, and $\mathrm{C}[9]$.

Clinical data and routine laboratory blood samples were collected at each visit. Each recorded visit, the mother was asked to answer a simple 14 items Mediterranean diet adherence screener questionnaire [10] to evaluate her diet compliance. A score of 9 of the 14 was the cut off point for discriminating between case and control [11] (Table 1).

According to Mediterranean diet adherence, participant pregnant women were divided into two groups:

Obese intervention group: Pregnant women who were compliant and adherent to diet. It included 57 participants (paired mother and newborn).

Table 1 Questionnaire for diet adherence evaluation

\begin{tabular}{|c|c|}
\hline \multicolumn{2}{|c|}{ Maternal diet adherence evaluation } \\
\hline Criteria & Description \\
\hline Use of olive oil as main fat & Yes or no \\
\hline Olive oil consumption & $>4$ tbsp/day \\
\hline Vegetables & $\begin{array}{l}\text { Two or more cups of vegetables } \\
\text { a day ( } 200 \mathrm{~g} \text { per serving) }\end{array}$ \\
\hline Fruit & Two or more pieces of fruit a day \\
\hline $\begin{array}{l}\text { Red or processed meat } \\
(1 \text { serving }=100-150 \mathrm{~g})\end{array}$ & 2 Servings or fewer a week \\
\hline $\begin{array}{l}\text { Servings of butter, margarine, } \\
\text { or cream ( } 1 \text { serving }=12 \mathrm{~g} \text { ) }\end{array}$ & $<1 /$ day \\
\hline Sweet or carbonated beverages & $<1 /$ day \\
\hline *Water & More than $11 \frac{1}{2} \mathrm{I} /$ day \\
\hline $\begin{array}{l}\text { Servings of legumes } \\
\text { (1 serving, } \sim 150 \mathrm{~g} \text { ) }\end{array}$ & 2 or more servings a week \\
\hline Nuts/seeds & $\begin{array}{l}\text { A handful of nuts most days } \\
\text { (> } 3 \text { weeks) }\end{array}$ \\
\hline $\begin{array}{l}\text { Servings of fish or shellfish } \\
\text { (1 serving, } 100 \text { Y } 150 \mathrm{~g} \text { of fish; } \\
4 \text { Y } 5 \text { units or } 200 \text { of shellfish) }\end{array}$ & $>3 /$ week \\
\hline $\begin{array}{l}\text { Consumption of commercial } \\
\text { (not homemade) sweets or } \\
\text { pastries }\end{array}$ & $<3 /$ week \\
\hline $\begin{array}{l}\text { Consume preferentially } \\
\text { chicken }\end{array}$ & Yes \\
\hline Whole grains & Two or more whole grains a day \\
\hline
\end{tabular}

*We substituted the wine drinks in the score by drinking water more than 1 liter per day 
Obese control group: pregnant women who were not adherent to diet instructions. It included 61 participants (paired mother and newborn) (Fig. 1).

Anthropometric measures:

1) Gestational age assessment.

2) Birth weight in kilogram.

3) Newborn length in centimeter.

4) Body mass index was calculated using the following formula: weight $(\mathrm{kg}) /$ length $\left(\mathrm{m}^{2}\right)$.

5) Skinfold thickness (SFT) measurements in millimeter taken from four different sites (tricepsbiceps-quadriceps-subscapular) using slim guide skinfold calipe0072 and their mean were calculated.

6) Body fat mass percentage using the following equation [12]:

$$
\begin{aligned}
& \text { Male : \%of body fat mass }=1.21 \times \sum \mathrm{SFT}^{2}-1.7 \\
& \text { Female }: \% \text { of body fat mass }=0.013 \times \sum \mathrm{SFT}^{2}-25
\end{aligned}
$$

\section{Blood sampling}

Three millimeters of maternal serum and cord blood was withdrawn from each participant (paired mother and newborn). Samples were collected under complete aseptic conditions in clean glass tubes without anticoagulant. After coagulation, serum was separated, aliquoted, and stored at $-20{ }^{\circ} \mathrm{C}$ for the assay of leptin.

\section{Analytical method}

Leptin assay was carried out using a commercially available product of DSL-10-23100 Active [Diagnostic

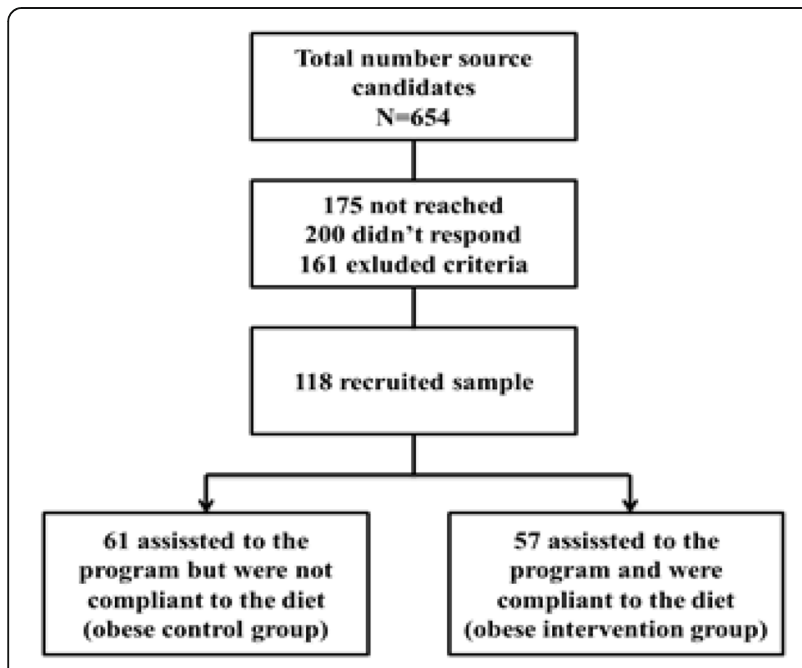

Fig. 1 Schematic representation of the study group
System Laboratories, Inc. (DSL): Corporate Headquarters, 445 Medical Center Blvd, Webster, Texas; 775984217, USA]. This assay is an enzymatically amplified two-step sandwich-type immunoassay performed in microtitration wells, which have been coated with antihuman leptin antibody. After incubation of serum and washing off the unbound leptin, the wells were treated with another antihuman leptin detection antibody labeled with the enzyme horseradish peroxidase (HRP). After a second incubation and washing step, the wells were incubated with the substrate tetramethylbenzidine (TMB). An acidic stopping solution was then added, and the degree of the enzymatic turnover of the substrate was determined by dual-wavelength absorbance measurement at 405 and $620 \mathrm{~nm}$. The absorbance measured is directly proportional to the concentration of human leptin present. A set of human leptin standards was used to plot a standard curve of absorbance versus human leptin conc. from which the human leptin concentration in subjects' sera was calculated using a linear curve-fit.

\section{Statistical methods}

Data were collected and analyzed using statistical package for social science (SPSS) version for windows (version 15.0.1). All data were expressed in terms of mean values \pm SD. Comparisons of parameters among groups were made using student $t$ test after testing and verification of normal distribution. Comparisons between two qualitative variables were performed using chi-square and fisher's exact tests. A $p$ value $\leq 0.05$ was significant. Pearson's correlation coefficient $(r)$ test was used for correlating data.

\section{Results}

The mean age of pregnant women included was $26 \pm$ 5.4 years, and the neonatal mean gestational age was 38 \pm 1.3 weeks. Anthropometric measures of the studied groups and leptin levels (maternal serum and cord blood) are shown in (Table 2).

The interventional Mediterranean diet had a negative effect on the gestational weight gain where the mother in the intervention group had significantly lower gestational weight gain as compared to the control (12.22 \pm $1.81 \mathrm{~kg}$ vs $18.03 \pm 3.25 \mathrm{~kg}, p=0)$. The mean birthweight and BMI of newborn of the intervention group were significantly lower than that of the control group (3.57 \pm 0.35 vs $4.02 \pm 0.32 \mathrm{~kg}[p=0]$ and $15.69 \pm 2.24$ vs 17.45 $\pm 2.36[p=0.001]$, respectively). Meanwhile, there were no significant differences in the mean gestational age or length between newborns of both groups.

Maternal serum leptin positively correlated with the gestational weight gain, fat mass $\%$, and cord leptin of the control group $(r=0.882, p=0.000 ; r 0.642, p=0.00$; and $r$ 0.977, $p=0.000$, respectively), but it did not 
Table 2 Anthropometric measures of the studied groups and leptin levels

\begin{tabular}{|c|c|c|c|c|c|c|}
\hline & & $\begin{array}{l}\text { Obese intervention group } \\
\text { No. }=57\end{array}$ & $\begin{array}{l}\text { Obese control group } \\
\text { No. }=61\end{array}$ & $\begin{array}{l}\text { Test } \\
\text { value. }\end{array}$ & $P$ value & Sig. \\
\hline \multirow[t]{2}{*}{ Maternal body mass index } & Mean \pm SD & $33.22 \pm 1.33$ & $33.25 \pm 1.32$ & 0.091 & 0.927 & NS \\
\hline & Range & $31-35$ & $31-35$ & & & \\
\hline \multirow[t]{2}{*}{ Gestational weight gain $(\mathbf{k g})$} & Mean \pm SD & $12.22 \pm 1.81$ & $18.03 \pm 3.25$ & 9.481 & 0.000 & HS \\
\hline & Range & $9-15$ & $12-23$ & & & \\
\hline \multirow[t]{2}{*}{ Gestational age (weeks) } & Mean \pm SD & $36.67 \pm 2.75$ & $36.80 \pm 2.65$ & 0.215 & 0.830 & NS \\
\hline & Range & $26-39$ & $26-39$ & & & \\
\hline \multirow[t]{2}{*}{ Length (cm) } & Mean \pm SD & $48.39 \pm 3.74$ & $48.38 \pm 3.56$ & -0.017 & 0.987 & NS \\
\hline & Range & $44-57$ & $44-57$ & & & \\
\hline \multirow[t]{2}{*}{ Birth weight (kg) } & Mean \pm SD & $3.57 \pm 0.35$ & $4.02 \pm 0.32$ & 5.780 & 0.000 & HS \\
\hline & Range & $3-4.2$ & $3.4-4.5$ & & & \\
\hline \multirow[t]{2}{*}{ Newborn body mass index } & Mean \pm SD & $15.69 \pm 2.24$ & $17.45 \pm 2.36$ & 3.328 & 0.001 & HS \\
\hline & Range & $11.1-18.8$ & $12.9-20.4$ & & & \\
\hline \multirow[t]{2}{*}{ Biceps (mm) } & Mean \pm SD & $4.53 \pm 0.35$ & $6.08 \pm 0.55$ & 14.371 & 0.000 & HS \\
\hline & Range & $3.8-5$ & $5.1-7$ & & & \\
\hline \multirow[t]{2}{*}{ Triceps (mm) } & Mean \pm SD & $5.13 \pm 0.46$ & $6.30 \pm 0.77$ & 7.918 & 0.000 & HS \\
\hline & Range & $4.1-6$ & $4.1-7.4$ & & & \\
\hline \multirow[t]{2}{*}{ Thigh (mm) } & Mean \pm SD & $6.91 \pm 0.54$ & $8.49 \pm 0.60$ & 11.967 & 0.000 & HS \\
\hline & Range & $6-7.9$ & $7.4-9.5$ & & & \\
\hline \multirow[t]{2}{*}{ Subscapular (mm) } & Mean \pm SD & $6.58 \pm 1.38$ & $7.72 \pm 1.67$ & 3.211 & 0.002 & HS \\
\hline & Range & $5-9.5$ & $5.9-11$ & & & \\
\hline \multirow[t]{2}{*}{ Average SC fat (mm) } & Mean \pm SD & $5.79 \pm 0.51$ & $7.14 \pm 0.74$ & 9.229 & 0.000 & HS \\
\hline & Range & $5.09-6.75$ & $5.95-8.5$ & & & \\
\hline \multirow[t]{2}{*}{ Fat mass $\%$} & Mean \pm SD & $9.27 \pm 2.16$ & $11.85 \pm 2.30$ & 5.014 & 0.000 & HS \\
\hline & Range & $6.36-12.8$ & $8.3-14.99$ & & & \\
\hline \multirow[t]{2}{*}{ Maternal leptin ng/ml } & Mean \pm SD & $20.19 \pm 4.14$ & $44.64 \pm 10.88$ & 12.670 & 0.000 & HS \\
\hline & Range & $13-28.5$ & $27-65$ & & & \\
\hline Cord leptin ng/ml & Mean \pm SD & $11.78 \pm 3.63$ & $35.37 \pm 11.14$ & 12.124 & 0.000 & HS \\
\hline
\end{tabular}

correlate significantly with that of the intervention group; cord leptin, meanwhile, had a significant positive correlation with gestational weight gain and fat mass $\%$ in the intervention group of the newborn $(r$ $=0.379, p$ value $=0.023$ and $r=0.556, p$ value $=<$ 0.001 , respectively), and in the control group also ( $r$ $=0.921, p$ value $<0.001$ and $r=0.645, p$ value < 0.001 , respectively) (Table 3 ).

\section{Discussion}

The dietary guidelines suggest the adoption of healthy eating patterns, which are characterized by higher consumption of fruits, vegetables, and whole grains and lower intake of calories, saturated fat, sodium, refined grains, and added sugars. One such healthy eating pattern contributing to overall health is the Mediterranean diet [13].

Table 3 Effect of Mediterranean diet intervention on studied parameters in both groups

\begin{tabular}{|c|c|c|c|c|c|c|c|c|c|c|c|c|}
\hline & \multicolumn{6}{|c|}{ Obese intervention group } & \multicolumn{6}{|c|}{ Obese control group } \\
\hline & \multicolumn{2}{|c|}{ Fat mass $\%$} & \multicolumn{2}{|c|}{ Maternal leptin ng/ml } & \multicolumn{2}{|c|}{ Cord leptin ng/ml } & \multicolumn{2}{|c|}{ Fat mass $\%$} & \multicolumn{2}{|c|}{ Maternal leptin ng/ml } & \multicolumn{2}{|c|}{ Cord leptin $\mathrm{ng} / \mathrm{ml}$} \\
\hline & $r$ & $P$ & $r$ & $P$ & $r$ & $P$ & $r$ & $P$ & $r$ & $P$ & $r$ & $P$ \\
\hline Maternal GWG & 0.627 & 0.000 & 0.195 & 0.227 & 0.379 & 0.023 & 0.565 & 0.000 & 0.882 & 0.000 & 0.921 & 0.000 \\
\hline Fat mass $\%$ & - & - & 0.123 & 0.731 & 0.556 & 0.000 & - & - & 0.642 & 0.000 & 0.645 & 0.000 \\
\hline Maternal leptin & - & - & - & - & 0.205 & 0.191 & - & - & - & - & 0.977 & 0.000 \\
\hline
\end{tabular}


In this study, it was hypothesized that dietetic counseling based on the Mediterranean diet (MD) might have a good impact on the appropriate intrauterine environment with neonatal influence on fat development and leptin level. To the best of our knowledge, it is the first study to assess the effect of the Mediterranean diet during pregnancy on cord leptin values and correlate it to infant fat mass percent.

The results of the present study have revealed that gestational weight gain, newborn birth weight, and cord leptin level were lower in the Mediterranean diet intervention group than the control group, with no significant differences in either maternal age or neonatal gestational age between both groups. Our findings are consistent with previous studies which suggested that both gestational weight gain and maternal adiposity have a main role in the determination of infant birth weight and macrosomia. In the study of Sommer et al. [14], gestational weight gain was the strongest independent predictor of both birth weight and neonatal sum of skinfolds, with a $0.21 \mathrm{~kg} /$ week increased weight gain giving a 110.7 (95\% confidence interval 76.6-144.9) g heavier neonate, and with $0.72(0.38-1.06) \mathrm{mm}$ larger sum of skinfolds.

Similarly, Hull et al. [15] reported that for women within the appropriate gestational weight gain category, infants born to obese mothers had greater \% fat (14.6\%) than infants born to normal-weight $(11.2 \%, P .014)$ and overweight mothers (9.2\%, $P$.002). For women within the excessive gestational weight gain category, infants born to normal-weight mothers had lower \%fat (11.8\%) than infants born to overweight mothers (13.7\%, $P$.019) and obese mothers (14.2\%, $P$.011). Moreover, gestational weight gain above the figures of the Institute of Medicine (IOM) guidelines was found to be associated with both macrosomia, and neonatal hypoglycemia in the study of Kominiarek et al. [16].

In the present study, the results revealed that skinfold thickness measurements and neonatal fat mass percent values were significantly lower in the intervention group than in the control group. This difference could be explained by the change in monounsaturated fat consumption and less total fat consumed during pregnancy and its positive correlation with the fetal adiposity and leptin level. The intervention group consumed mainly olive oil rich in useful fatty acids, polyunsaturated compounds, and also fat-soluble vitamins (A, E, D, and K): This finding consolidates the assumption that maternal nutritional status is an important determinant of intrauterine growth and neonatal size. Several studies have highlighted the benefits that adherence to the Mediterranean diet during pregnancy could have on the offsprings [17]. In the study of Lee et al. [18], supplementation of fish oils rich in eicosapentaenoic acid (EPA) and docosahexaenoic acid (DHA) to overweight women during gestation has shown a protective effect to fetal growth and development. These protective effects of fish oils were associated with increased DNA methylation of insulin growth factor 2 (IGF2), which controls intrauterine and postnatal growth.

Therefore, it goes with our hypothesis that fetal leptin levels may be involved in fetal development during late pregnancy.

Our findings also revealed that the cord leptin levels strongly correlated with the average gestational weight gain and neonatal fat mass percent in both study groups. Maternal serum leptin was found to be associated with the fat mass percent and cord leptin levels in the control group. Therefore, our findings support the hypothesis that fetal leptin levels may be involved in fetal development during late pregnancy. In a cohort study done on 638 motherchild pairs providing cord blood serum samples for leptin analysis and complete data on birth outcomes, it was found that both an increased birth size and longer gestational age are associated with higher cord blood leptin levels and that maternal pre-pregnancy BMI and weight gain during pregnancy represented significant indicators of cord blood leptin [19]. These findings are in agreement with our results. Another study conducted on 39 women and their babies to assess the link between leptin level and neonatal adiposity revealed a strong association between maternal leptin and maternal adiposity in pregnancy, and also between cord leptin at delivery and birthweight, as well as other anthropometric markers of fetal growth [20]. Similar results had been also previously obtained by others [21]. It was reported that the synthesis of leptin is in the placenta and that leptin concentration in the cord blood correlates with newborn anthropometry. In addition, umbilical serum leptin levels were found to correlate positively with neonatal birth weights [22]. Several physiological roles for leptin in pregnancy have been proposed, including the regulation of fetal growth and development, fetal/placental angiogenesis, embryonic hematopoiesis, and hormone biosynthesis within the maternal-fetoplacental unit. The specific localization of both leptin and its receptor in the syncytiotrophoblast implies autocrine and/or paracrine relationships in this endocrinologically active tissue [23].

\section{Limitations}

The limitations of the study are the focus on superficial adiposity and no access to the visceral and intraabdominal fat.

\section{Conclusion}

We found that the energy intake from healthy fat and diet was associated with decreased fat mass and leptin level in neonates. These findings indicate that the composition of the maternal diet is important for birth outcomes. An association between fat intake and birth outcomes should be more investigated in the future studies. 


\section{Abbreviations}

BMl: Body mass index; GWG: Gestational weight gain; MD: Mediterranian diet; SFT: Skinfold thickness

\section{Acknowledgements}

Not applicable

\section{Authors' contributions}

R.A conceived of the study, participated in its design and coordination, and performed the nutritional assessment and anthropometric measures. G.E performed the maternal gestational nutritional assessment and counseling and analyzed and interpreted the patient data. A.S performed the laboratory work-up of the study and was a major contributor in writing the manuscript, analyzing, and interpreting the patient data. The authors read and approved the final manuscript.

\section{Funding}

The authors did not receive any funding.

\section{Availability of data and materials}

All data generated and/or analyzed during this study are included in this published article (and its supplementary information files).

\section{Ethics approval and consent to participate}

This was a cross-sectional study conducted at the antenatal clinic as a part of the gestational nutritional counseling program and neonatal intensive care unit of Ain Shams University hospital for one and a half years starting June 2016. The protocol for this study was approved by the Research Ethical Committee of Ain Shams University hospitals; ID: FMASU MS 27/2016. A verbal informed consent was obtained from pregnant women to be enrolled in the study as no invasive procedures are included and the follow-up is a part of the routine antenatal care.

\section{Consent for publication}

Not applicable

\section{Competing interests}

The authors declare that they have no competing interests.

\section{Author details}

${ }^{1}$ Department of Pediatrics, Faculty of Medicine, Ain Shams University, Cairo, Egypt. ${ }^{2}$ Department of Obstetrics \& Gynecology, Faculty of Medicine, Ain Shams University, Cairo, Egypt. ${ }^{3}$ Department of Clinical Pathology, Faculty of Medicine, Ain Shams University, Cairo, Egypt.

Received: 3 July 2019 Accepted: 1 September 2020

Published online: 30 September 2020

\section{References}

1. Thornburg KL, Valent AM (2018) The maternal nutritional milieu and neonatal outcomes. Connecting the dots. J Pediatr 195(9-11)

2. Yu Z, Han S, Zhu J, Sun X, Ji C, Guo X (2013) Pre-pregnancy body mass index in relation to infant birth weight and offspring overweight/obesity: a systematic review and meta-analysis. PLoS ONE 8(4):e61627

3. Wittcopp $\mathrm{CH}$, Conroy R (2016) Metabolic syndrome in children and adolescents. Pediatr Rev 37(5):37-39

4. Huo R, Du T, Xu Y, Xu W, Chen X, Sun K et al (2015) Effects of Mediterranean-style diet on glycemic control, weight loss and cardiovascular risk factors among type 2 diabetes individuals: a metaanalysis. Eur J Clin Nutr 69(11):1200-1208

5. Kastorini CM, Milionis HJ, Esposito K, Giugliano D, Goudevenos JA, Panagiotakos DB (2011) The effect of Mediterranean diet on metabolic syndrome and its components: a meta-analysis of 50 studies and 534,906 individuals. J Am Coll Cardiol 57(11):1299-1313

6. Lorite Mingot D, Gesteiro E, Bastida S, Sánchez-Muniz FJ (2017) Epigenetic effects of the pregnancy Mediterranean diet adherence on the offspring metabolic syndrome markers. J Physiol Biochem 73(4):495-510

7. Evain-brion D, Malassine A (2003) Human placenta as an endocrine organ. Growth Hormon IGF Res 13(A):S34-S37

8. Clapp JF, Kiess W (1998) Cord blood leptin reflects fetal fat mass. J Soc Gynecol Investig 5(6):300-303
9. Bach-Faig A, Berry EM, Lairon D, Reguant J, Trichoupoulou A, Dernini S et al (2011) Mediterranean diet pyramid today. Science and cultural updates. Public Health Nutr 14(12A):2274-2284

10. Martínez-González MA, Corella D, Salas-Salvadó J, Ros E, Covas MI et al (2012) Cohort profile: design and methods of the PREDIMED study. Int J Epidemiol 41:377-385

11. Martínez-González MA, Fernández-Jarne E, Serrano-Martínez M, Wright M, Gomez-Gracia E (2004) Development of a short dietary intake questionnaire for the quantitative estimation of adherence to a cardioprotective Mediterranean diet. Eur J Clin Nutr 58:1550-1552

12. Hansjörg RS, Christoph F (2002) Body fat in neonates and young infants: validation of skinfold thickness versus dual-energy X-ray absorptiometry. Am J Clin Nutr 76:1096-1100

13. Van Horn L, Carson JA, Appel LJ, Burke LE, Economos C, Karmally W et al (2016) Recommended dietary pattern to achieve adherence to the American Heart Association/American College of Cardiology (AHA/ACC) Guidelines: a scientific statement from the American Heart Association. Circulation. 134(22):e505-e529

14. Sommer C, Sletner L, Mørkrid K, Jenum AK, Birkeland KI (2015) Effects of early pregnancy BMI, mid-gestational weight gain, glucose and lipid levels in pregnancy on offspring's birth weight and subcutaneous fat: a population-based cohort study. BMC Pregnancy Childbirth 15:84

15. Hull HR, Thornton JC, Ji Y, Paley C, Rosenn B, Mathews P et al (2011) Higher infant body fat with excessive gestational weight gain in overweight women. Am J Obstet Gynecol 205(3):211.e1-211.e7

16. Kominiarek MA, Saade G, Mele L, Bailit J, Reddy UM, Wapner RJ et al (2018) Association between gestational weight gain and perinatal outcomes. Obstet Gynecol 132(4):875-881

17. Rasouli N, Kern PA (2008 Nov) Adipocytokines and the metabolic complications of obesity. J Clin Endocrinol Metab 93(11Suppl 1):S64-S73

18. Lee HS, Barraza-Villarreal A, Biessy C, Duarte-Salles T, Sly PD, Ramakrishman $U$ et al (2014) Dietary supplementation with polyunsaturated fatty acid during pregnancy modulates DNA methylation at IGF2/H19 imprinted genes and growth of infants. Physiol Genomics 46(23):851-857

19. Karakosta P, Georgiou V, Fthenou E, Papadopoulou E, Roumeliotaki T, Margioris A et al (2013) Maternal weight status, cord blood leptin and fetal growth: a prospective mother-child cohort study (Rhea study). Paediatr Perinat Epidemiol 27(5):461-471

20. Geary M, Pringle PJ, Persaud M, Wilshin J, Hindmarsh PC, Rodeck CH et al (1999) Leptin concentrations in maternal serum and cord blood: relationship to maternal anthropometry and fetal growth. Br J Obstet Gynaecol 106(10):1054-1060

21. Donnelly JM, Lindsay KL, Walsh JM, Horan M, Molloy EJ, Mc Auliffe FM (2015) Fetal metabolic infuences of neonatal anthropometry and adiposity. BMC Pediatr 15:175

22. Hoggard N, Haggarty P, Thomas L, Lea RG (2001) Leptin expression in placental and fetal tissues: does leptin have a functional role? Biochem Soc Trans 29(Pt 2):57-63

23. Tessiera DR, Ferraro ZM, Gruslin A (2013) Role of leptin in pregnancy: consequences of maternal obesity. Placenta. (3):205-211

\section{Publisher's Note}

Springer Nature remains neutral with regard to jurisdictional claims in published maps and institutional affiliations. 